\title{
Possible Pathogenetic Mechanisms and New Therapeutic Approaches of Pes Equinovarus
}

\author{
M. OŠŤÁDAL ${ }^{1}$, J. LIŠKOVÁ ${ }^{2}$, D. HADRABA ${ }^{2,3}$, A. ECKHARDT ${ }^{2}$ \\ ${ }^{1}$ Department of Orthopaedics, First Faculty of Medicine, University Hospital Bulovka, Prague, \\ Czech Republic, ${ }^{2}$ Institute of Physiology, Czech Academy of Sciences, Prague, Czech Republic, \\ ${ }^{3}$ Biomedical Research Institute, Hasselt University, Belgium
}

Received June 10, 2016

Accepted December, 2016

On-line February 28, 2017

\section{Summary}

Idiopathic pes equinovarus (clubfoot) is a congenital deformity of the foot and lower leg defined as a fixation of the foot in plantar flexion, adduction, supination and varus. The deformity does not affect only the foot position, which is usually investigated by radiography, $\mathrm{CT}$, micro-CT, MRI or ultrasound but logically influence the whole gait biomechanics. It is supposed, that clubfoot belongs to a group of fibroproliferative disorders whose origin and multi-hierarchical effect remain unknown. It has been suggested that fibroblasts and growth factors may be involved. To gain a more global view, direct analysis of the protein composition of extracellular matrix, a proteomic approach was used. At present two principle methods are mostly used for the treatment of clubfoot: physiotherapy and the Ponseti method. The determination of the general biological and biomechanical parameters for various regions of the clubfoot can potentially help in the understanding of the mechanisms participating on this serious anomaly and thus contribute to the development of the more efficient therapeutic approach. This review summarizes the present knowledge on the possible pathogenetic mechanisms participating in the development of the clubfoot and their possible relation to the new therapeutic approaches.

\section{Key words}

Pes equinovarus • Clubfoot $\bullet$ Pathogenetic mechanisms • Fibrosis

\section{Corresponding author}

M. Ostadal, Department of Orthopaedics, First Faculty of Medicine, University Hospital Bulovka, Charles University,
Budínova 2, 18000 Prague 8, Czech Republic. E-mail: martinostadal@yahoo.com

\section{Introduction}

Idiopathic pes equinovarus (also referred to as clubfoot) is a congenital deformity of the foot and lower leg, defined as a fixation of the foot in plantar flexion, adduction, supination, and varus, with concomitant abnormalities present at birth. The incidence among Caucasians is around 1 per 1,000 live births, in Japan 0.56 per 1,000 and among natives of the South Pacific region nearly 7 per 1,000 live births. Data on the sex differences in the incidence of clubfoot are not concise. In general, we can find in the literature the ratio between boys and girls of 2:1, in our group of patients (Oštádal et al. 2013) the male to female ratio was 3:1, Morcuende et al. (2004) indicated even the ratio of 4:1. Most clubfeet develop in otherwise normal children toward the middle of gravidity. Exceptionally, the first signs of this deformity can be observed on ultrasonography already by the end of the $16^{\text {th }}$ week of gravidity. The most severe deformities in a clubfoot occur in the hind part of the foot. The talus and calcaneus are generally deformed and in severe equinus, the calcaneus is in varus angulation and medially rotated, and the navicular is severely displaced medially and may be in contact with the medial malleolus. Pathogenetic mechanisms of the development of clubfeet are, unfortunately, not known. Many theories have been proposed to explain its etiology, including 
primary defect of the embryonic mesenchyme, induced by an unknown toxic effect before the seventh week of intrauterine development. Most cases of this malformation occur as an isolated birth defect and are considered idiopathic.

This review summarizes the present knowledge on the possible pathogenetic mechanisms participating in the development of the clubfoot and their possible relation to the new therapeutic approaches, including our own experience (Oštádal et al. 2013, Oštádal et al. 2015).

\section{Possible pathogenetic mechanisms}

The pathogenesis of clubfoot remains unclear (Ošt'ádal et al. 2015). Many theories have been proposed to explain its etiology, including vascular deficiencies in the talus (Irani and Sherman 1972), environmental factors, in utero poisoning (Dunn 1972), abnormal muscle insertions (Bonnell and Cruess 1969), and genetic factors (Gurnett et al. 2008). While it is becoming more obvious that clubfoot is multifactorial in origin, genetics clearly play a role, as indicated by the familial pattern of inheritance and a $32.5 \%$ concordance between monozygotic twins (Lochmiller et al. 1998). Although the exact genetic mechanisms of clubfoot has yet to be elucidated, a multifactorial and, possibly, polygenic causation has been suggested. The search for possible "clubfoot susceptibility" genes is underway; two transcription factor genes, PITXI and TBX4, have attracted attention. The PITX1-TBX4 pathway is responsible for early limb development, with both playing a role in hind limb development but being minimally expressed in the forelimb, perhaps explaining why there is no equivalent of clubfoot in the upper limb (Gurnett et al. 2008). Recent studies assessed the functionality of potential regulatory variants, rs3801776/HOXA9, rs2025126/TPM2, rs2145925/ TPM2, and rs4075583/TPM1, to be associated with clubfoot (Weymouth et al. 2011, Weymouth et al. 2016).

\section{Classification methods and biomechanical indicators}

The initial classification of the deformity targets the bone positioning is conducted by radiography (Pandey and Pandey 2003); the targeted bones are mainly os calcaneus and os talus. According to Heywood (1964) the talo-calcaneal angle is often reduced in clubfoot compared to normal foot. Hosking and Scott's (1982) biomechanical study on cadavers suggested much greater subtalar movement during dorsiflexion in clubfoot. In addition, this talocalcaneal region contains the maximum contracted part of the fibrotic tissue; this tissue is similar to the intervertebral disc and therefore named "disc-like tissue" (Hersh 1967). Fukuhara (1994) studied this tissue using immunohistochemical staining and observed regular parallel collagen fibers in normal foot; on the other hand, a disrupted collagen pattern was revealed in clubfoot. Foster and Davis (2007) used electron microscope to discover an increase in waviness and density of collagen fibers. Nowadays, modern methods such as micro-CT, CT, MRI and Doppler ultrasound (Cooke et al. 2008) tend to study the tissue directly with in vivo potential. The results are either used for 3D models, for instance for custom orthosis (Vijayaragavan et al. 2014), clubfoot surgical model (Windisch et al. 2007) or for comparison with foot pressure and gait biomechanical analysis at clubfoot (Herd et al. 2004). This combination of methods was able to reveal some functional abnormalities even at corrected and well-functioned clubfoot (Hee et al. 2001).

\section{Cell type in clubfoot fibrous tissue}

The cells from the contracted "disc-like tissue" region express high levels of type III collagen (Fukuhara 1994, Gilbert 2001, Li 2001), however the consequent changes of morphology are unknown. Furthermore, cells from fibroproliferative disorders such as palmar fibromatosis and the contracted tissues in clubfoot express several growth factors including platelet-derived growth factor (PDGF) and the transforming growth factor beta (TGF $\beta)$. PDGF and TGF $\beta$ are well known inducers of tissue injury healing, but they also play role as factors involved in tissue fibrosis process. The blockade of PDGF and TGF $\beta$ led to decreased collagen expression, fibroblast proliferation and chemotaxis, which would alter the tissue properties ( $\mathrm{Li}$ 2001). It has been suggested that the expression of these factors may not be the primary cause of contracture, but may instead be secondary to the activation of another signalling pathway, such as beta-catenin-mediated signalling, which may play a central role in regulating the contracture in clubfoot (Cheon 2004, Poon 2009).

All of these studies support the hypothesis that fibroblast-like cells and growth factors are involved in the pathogenetic mechanisms which is responsible for the 
morphological and functional changes in clubfoot. However, there is no general agreement on the cell classification in the published papers; the cells in disc-like tissue might be connective tissue fibroblasts, fibrocytes of hematopoetic origin, with high cytokine production (Peng 2012), or myofibroblasts possessing fibroblast characteristics and expressing smooth muscle markers (Sano 1998, Poon 2009).

\section{The role of collagens and other extracellular matrix proteins}

We have observed during the surgery that the macroscopic structure of the connective tissue is different on the medial and lateral parts of the tarsus: the medial part is more rigid (Ošt’ádal et al. 2015). This observation supports the hypothesis that connective tissue, particularly fibroblasts and growth factors are involved in the pathogenetic mechanisms responsible for the development of clubfoot. To obtain a more global understanding of the protein composition of the extracellular matrix, we performed the proteomic analysis of the connective tissue in patients with clubfoot. We hypothesized that identification of individual proteins may help to understand the mechanisms involved in this serious anomaly and, thus, contribute to the development of more efficacious therapeutic strategies (Ošt'ádal et al. 2015).

Only one study tried to explore the etiology of idiopathic talipes equinovarus in all-trans retinoic acid (ATRA) induced clubfoot-like deformity in rat fetuses with two-dimensional gel electrophoresis and mass spectrometry. The results suggest that there are certain differently expressed proteins in ankle joint tissue, ankle joint bone and spinal cord of the ATRA-induced clubfoot-like deformity in rat fetuses, and X-linked inhibitor of apoptosis protein, troponin $\mathrm{T}$ type 1 , and collagen type II alpha 1 show a significant correlation with idiopathic talipes equinovarus (Li et al. 2007).

Collagens represent a family of matrix molecules used by cells for structural integrity and function. The three $\alpha$ chains that form the triple helical part of the molecule are composed of repeating peptide triplets of glycine-X-Y. In this triplet, $\mathrm{X}$ is often proline and $\mathrm{Y}$ is frequently hydroxyproline. From a total of 28 different collagen types described until now (Gordon and Hahn 2010), first five types are prevailing in human body. The major part of extracellular matrix in clubfoot is formed by collagen types I and III. Type I collagen is most abundant in skin, tendon, ligament, bone, cornea etc. where it comprises between $80 \%$ and $99 \%$ of the total collagen. The proportion of type I collagen in a particular tissue can vary at different sites, during development and pathology. Type III collagen is a normal constituent of skin $(10 \%-20 \%)$ but it has been found in many other connective tissues. It is present in variable amounts associated with type I collagen. Ratio of types I to III collagen changes significantly during ontogenetic development: in early fetal life type III collagen is more abundant than type I. Similarly, a preponderance of type III and later reversion in the III:I ratio towards normal has been observed in dermal wound repair (Nimni et al. 1983). In case of clubfeet biopsy of the capsule of the ankle joint, the number of hydroxylysine residues and the number of pyridinium crosslinks per collagen molecule were normal. This indicates normal processing of collagen molecules and normal alignment of collagen molecules within fibrils despite the variety of clubfeet, and even in scar tissue (Sluijs and Pruys 1999).

It has been observed for the first time that extracellular matrix of clubfoot is composed also from collagens type V, VI and XII (Ošt’ádal et al. 2015). Type $\mathrm{V}$ collagen seems to be particularly abundant in vascular tissues, where it appears to be synthesized by smooth muscle cells. In differentiated cartilage, antibodies to type $\mathrm{V}$ collagen localize around the pericellular matrix within the chondrocyte lacunae (Gay et al. 1981, Chen et al. 2014). Microfibrillar collagen type VI is a unique member of the collagen family that is ubiquitously expressed throughout the extracellular matrix (Gordon and Hahn 2010, Sabatelli et al. 2012a, Sabatelli et al. 2012b). Collagen VI is present in human connective tissues such as those of the joint capsule ligament, tendons, and skin. In fact, the major function proposed for collagen VI is an anchoring meshwork that connects collagen fibers to the surrounding matrix (Groulx et al. 2011). Type VI collagen has a crucial role in the function in muscle, since mutation causes Bethlem myopathy and Ulrich congenital muscular dystrophy (Lampe and Bushby 2005, Kim et al. 2012). Muscles lacking collagen VI are characterized by the presence of dilated sarcoplasmic reticulum and dysfunctional mitochondria (Grumati et al. 2011). Latent mitochondrial dysfunction is present both in muscle cells and in fibroblasts derived from muscles cultures of patients suffering from the above mentioned muscular dystrophies, suggesting the important role of mitochondria in the pathogenesis of these disorders 
(Sabatelli et al. 2012a). Collagen XII is a member of FACIT collagens (Fibril Associated Collagens with Interrupted Triple helices), it is overexpressed in permanent human and mouse corneal scars (Massoudi et al. 2012).

The extracellular matrix in clubfoot is, except collagens, also composed at least of 13 proteins including protein $\mathrm{ABI} 3 \mathrm{~PB}$ (capable binding collagen VI), small leucin-rich proteoglycan biglycan, leucin-rich proteoglycans asporin and prolargin, proteoglycan osteoglycin/mimecan, oxidative stress-sensitive proteoglycan fibromodulin, keratan sulfate proteoglycan lumican, membrane primary amine oxidase, large fibroblast proteoglycan versican, extracellular matrix glycoprotein tenascin- $x$ exclusively expressed in fibroblasts, high-molecular weight glycoprotein fibronectin, TGF $\beta$-inducible matricellular protein periostin, and TGF $\beta$-induced protein IG-H3 (Oštádal et al. 2015). Available information regarding the function of other proteins that were observed for the first time in the extracellular matrix in clubfoot (Table 1) is, unfortunately, sparse. For instance, small leucine-rich proteoglycans, such as biglycan, are involved in collagen fibril assembly and its fragmentation is likely to be associated with collagen turnover during the pathogenesis of diseases that involve deregulated collagen matrix remodeling (Genovese et al. 2013). The data comparing the composition of extracellular matrix in clubfoot and normal foot are, unfortunately, not available. The reason is obviously the absence of relevant tissue samples from normal foot. We can, therefore, only speculate on the basis of our macroscopic observations that the increased rigidity of the tissue from the medial part of clubfoot is connected with different protein composition. Detailed analysis should be the matter of further experimental and clinical investigation.

Table 1. List of proteins detected by proteomic analysis.

\begin{tabular}{|c|c|c|}
\hline Protein Name & Detected peptides & Molecular Function \\
\hline Collagen type I alpha-1 chain & 104 & Extracellular matrix structural constituent \\
\hline Collagen type I alpha-2 chain & 78 & Extracellular matrix structural constituent \\
\hline Collagen type III alpha-1 chain & 51 & Extracellular matrix structural constituent \\
\hline Collagen type VI alpha-3 chain & 39 & Extracellular matrix structural constituent \\
\hline Collagen type VI alpha-1 chain & 19 & Extracellular matrix structural constituent \\
\hline Collagen type VI alpha-2 chain & 17 & Extracellular matrix structural constituent \\
\hline Biglycan & 10 & Extracellular matrix structural constituent \\
\hline Prolargin & 9 & Extracellular matrix structural constituent \\
\hline Osteoglycin (Mimecan) & 7 & Extracellular matrix structural constituent \\
\hline Fibromodulin & 8 & Extracellular matrix structural constituent \\
\hline $\begin{array}{l}\text { Transforming growth factor- } \beta \text { - } \\
\text { induced protein ig- } h 3\end{array}$ & 8 & Extracellular matrix structural constituent \\
\hline Lumican & 6 & Extracellular matrix structural constituent \\
\hline Collagen alpha-1(XII) chain & 5 & Cytoskeletal anchoring activity \\
\hline Asporin & 7 & Growth factor activity \\
\hline Membrane primary amine oxidase & 4 & Extracellular matrix structural constituent \\
\hline Versican & 5 & Receptor binding \\
\hline Collagen alpha-1(V) chain & 2 & Extracellular matrix structural constituent \\
\hline Tenascin & 5 & Extracellular matrix structural constituent \\
\hline Fibronectin & 3 & Extracellular matrix structural constituent \\
\hline Periostin & 3 & Cell adhesion molecule activity \\
\hline
\end{tabular}

Peptides $=$ number of unique peptides detected in samples. The molecular functions of proteins in biological processes were categorized according to the classification system used in the public database available at http://www.hprd.org. 


\section{New therapeutic approach}

When untreated, children with clubfeet walk on the sides of their feet instead of the soles, resulting in infections, callus formation, arthritis and significant limitations in mobility and employment opportunities. The goal of treatment is to reduce or eliminate the deformities so that the patient has a functional, pain-free, plantigrade foot, with good mobility and without calluses, and does not need to wear modified shoes.

At present two principle methods are mostly used for the treatment of clubfoot: physiotherapy and continuous motion without immobilization (Diméglio et al. 1996) and the Ponseti method, described more than 50 years ago (Ponseti and Smoley 1963). The essential principles of the original Ponseti method (serial manipulation, a specific technique of cast application and a possible percutaneous Achilles tenotomy) were recently summarized elsewhere (Dobbs et al. 2004, Ponseti et al. 2006). At our institution the following regimen is used (Dungl et al. 2014). Treatment starts as soon as possible after referral, preferably shortly after birth, and consists of gentle manipulation of the foot and the serial application of long leg plaster casts above the knee as described by Ponseti (2006). In all patients, the cavus is corrected first by supinating the forefoot and dorsiflexing the first metatarsal. Failure to supinate the forefoot as the first step ultimately leads to incomplete correction of the clubfoot. If residual equinus is observed after the abduction of the foot and the varus deformity of the heel has been corrected, a simple percutaneous tenotomy in the operating room with the patient under short general anesthesia is performed, which allows optimal analgesia for the infant. We use local anesthesia only in cases when general anesthesia is contraindicated for different medical reasons. After the tenotomy the additional cast is applied to prevent relapse of the deformity (Oštádal et al. 2013).

Three weeks later, an orthosis is applied to prevent relapse of the deformity. The orthosis is worn full-time ( 23 to $24 \mathrm{~h}$ a day) first three months nonstop, and 14 to $16 \mathrm{~h}$ for the next three years during the night and day sleeping. To help prevent a recurrent equinus contracture, we have introduced - in addition to the original Ponseti method - the exercise of patients with their parents (Ošt’ádal et al. 2013). They are instructed about and given a handout on how to effectively perform range-of-motion exercises for the ankle when it is out of the brace. These exercises have improved our ability to effectively maintain the ankle motion achieved at the time of the tenotomy. The orthosis is removed at the age of 3 to 6 years. The exercise continues until skeletal maturity is reached. If conservative treatment of the relapse is unsuccessful in this age group, we proceed to surgical treatment. In the relapsing patients older than 3 years, we prefer to use a surgical approach.

We have observed significant difference between the evaluation of the short-term and long-term results of the Ponseti method in the treatment of idiopathic pes equinovarus (Oštádal et al. 2013). The number of relapses during the last three years of the eight years treatment of our group of patients, indicated for surgical intervention, was markedly less $(5 \%)$ as compared with patients where the treatment started 8-10 years ago $(65 \%)$.

Conservative management of intractable relapses by casting in patients older than three years is according to our experience very difficult because of maturation and decreased compliance of the fibrotic tissue (Ošt'ádal et al. 2013). Despite the knowledge of some rare complications (Dogan et al. 2008), Achilles tenotomy should be taken as a more conservative method than trying to aggressively treat with casts (Iltar et al. 2010). We are convinced, therefore, that the complex treatment of this defect requires not only exact knowledge of the conservative approach but also the set of different surgical interventions.

\section{Conclusions}

Pathogeny of pes equinovarus is, unfortunately, still not clear. The determination of general proteomic parameters for various regions of the clubfoot may serve as a basis for future studies characterizing extracellular matrix proteomes to provide molecular insight into various disease states and potential therapeutic interventions. The subsequent analysis of the mechanisms that regulate extracellular matrix remodeling and formation of contracture will be important for understanding the biology of this pathological process and the implementation of preventive or therapeutic strategies, like to use of enzymes for degradation of collagen VI in clubfoot.

\section{Conflict of Interest}

There is no conflict of interest.

\section{Acknowledgements}

This work was supported by the Ministry of Health 
Departmental Program for Research and Development development of research organization RVO: 67985823.

(15-29153A), and with support for long-term conceptual

\section{References}

BONNELL J, CRUESS RL: Anomalous insertion of the soleus muscle as a cause of foxed equinus deformity. a case report. J Bone Joint Surg Am 51: 999-1000, 1969.

CHEN W, ROCK JB, YEARSLEY MM: Different collagen types show distinct rates of increase from early to late stages of hepatitis C-related liver fibrosis. Hum Pathol 45: 160-165, 2014.

CHEON SS, NADESAN P, POON R, ALMAN BA: Growth factors regulate beta-catenin-mediated TCF-dependent transcriptional activation in fibroblasts during the proliferative phase of wound healing. Exp Cell Res 293 : 267-274, 2004.

COOKE SJ, BALAIN B, KERIN CC, KIELY NT: Clubfoot. Current Orthopaedics 22: 139-149, 2008.

DIMÉGLIO A, BONNET F, MAZEAU P, DE ROSA V: Ortopaedic treatment and passive motion machine: consequences for the surgical treatment of clubfoot. J Pediatr Orthop B 3: 173-180, 1996.

DOBBS MB, RUDZKI JR, PURCELL DB, WALTON T, PORTER KR, GURNETT CA: Factors predictive of outcome after use of the Ponseti method for the treatment of idiopathic clubfeet. J Bone Joint Surg Am 86: 22-27, 2004.

DOGAN A, KALENDAR AM, SERAMET E, USLU M, SEBIK A: Mini-open technique for the Achilles tenotomy in correction of idiopathic clubfoot: a report of 25 cases. J Am Podiatr Med Assoc 98: 414-417, 2008.

DUNGL P, ET AL.: Ortopedie. The 2nd Edition, Grada Publishing, Prague, 2014, pp 956-959.

DUNN PM: Congenital postural deformities: perinatal associations. Proc R Soc Med 65: 735-738, 1972.

FOSTER A, DAVIS N: Congenital talipes equinovarus (clubfoot). Surgery 25: 171-175, 2007.

FUKUHARA K, SCHOLLMEIER G, UHTHOFF HK: The pathogenesis of club foot. A histomorphometric and immunohistochemical study of fetuses. J Bone Joint Surg Br 76: 450-457, 1994.

GAY S, RHODES RK, GAY RE, MILLER EJ: Collagen molecules comprised of alpha 1(V)-chains (B-chains): an apparent localization in the exocytoskeleton. Coll Relat Res 1: 53-58, 1981.

GILBERT JA, ROACH HI, CLARKE NM. Histological abnormalities of the calcaneum in congenital talipes equinovarus. J Orthop Sci 6: 519-526, 2001.

GORDON MK, HAHN RA: Collagens. Cell Tissue Res 339: 247-257, 2010.

GROULX JF, GAGNÉ D, BENOIT YD, MARTEL D, BASORA N, BEAULIEU JF: Collagen VI is a basement membrane component that regulates epithelial cell-fibronectin interactions. Matrix Biol 30: 195-206, 2011.

GRUMATI P, COLETTO L, SANDRI M, BONALDO P: Autophagy induction rescues muscular dystrophy. Autophagy 7: 426-428, 2011.

GURNETT CA, ALAEE F, KRUSE LM, DESRUISSEAU DM, HECHT JT, WISE CA, BOWCOCK AM, DOBBS MB: Asymmetric lower-limb malformations in individuals with homeobox PITX1 gene mutation. Am J Hum Genet 83: 616-622, 2008.

HEE HT, LEE EH, LEE GS: Gait and pedobarographic patterns of surgically treated clubfeet. J Foot Ankle Surg 40: 287-294, 2001.

HERD F, MACNICOL M, ABBOUD RJ: The need for biomechanical evaluation in the assessment of clubfoot. Foot 14: 72-76, 2004.

HERSH A: The role of surgery in the treatment of club feet. J Bone Joint Surg Am 49: 1684-1696, 1967.

HEYWOOD AW: The mechanics of the hind foot in club foot as demonstrated radiographically. J Bone Joint Surg Br 46: 102-107, 1964.

HOSKING SW, SCOTT W: A study of anatomy and biomechanics of the ankle region in normal and club feet (talipes equino varus) of infants. J Anat 134: 227-236, 1982.

ILTAR S, UYSAL M, ALEMDAROGLU KB, AYDOGAN NH, KARA T, ATLIHAN D: Treatment of clubfoot with the Ponseti method: should we begin casting in the newborn period or later? J Foot Ankle Surg 49: 426-431, 2010 . 
KIM J, JIMENEZ-MALLEBRERA C, FOLEY AR, FERNANDEZ-FUENTE M, BROWN SC, TORELLI S, FENG L, SEWRY CA, MUNTONI F: Flow cytometry analysis: a quantitative method for collagen VI deficiency screening. Neuromuscul Disord 22: 139-148, 2012.

LAMPE AK, BUSHBY KM: Collagen VI related muscle disorders. J Med Genet 42: 673-685, 2005.

LI C, NGUYEN Q, COLE WG, ALMAN BA: Potential treatment for clubfeet based on growth factor blockade. J Pediatr Orthop 21: 372-377, 2001.

LI ZG, JI H, FU WN, ZHAO YY, JIN CL, JI SJ, SUN KL: Proteomic analysis of the ankle joint bone, ankle joint tissue and spinal cord of clubfoot-like deformity in rat fetuses. Chinese J Med Gen 24: 52-58, 2007.

LOCHMILLER C, JOHNSTON D, SCOTT A, RISMAN M, HECHT JT: Genetic epidemiology study of idiopathic talipes equinovarus. Am J Med Genet 79: 90-96, 1998.

MASSOUDI D, MALECAZE F, SOLER V, BUTTERWORTH J, ERRAUD A, FOURNIÉ P, KOCH M, GALIACY SD: NC1 long and NC3 short splice variants of type XII collagen are overexpressed during corneal scarring. Invest Ophthalmol Vis Sci 53: 7246-7256, 2012.

MORCUENDE JA, DOLAN LA, DIETZ FR, PONSETI IV: Radical reduction in the rate of extensive corrective surgery for clubfoot using the Ponseti method. Pediatrics 113: 376-380, 2004.

NIMNI ME: Collagen: structure, function, and metabolism in normal and fibrotic tissues. Semin Arthritis Rheum 13: $1-86,1983$.

OŠŤÁDAL M, CHOMIAK J, DUNGL P, FRYDRYCHOVÁ M, BURIAN M: Comparison of the short-term and long-term results of the Ponseti method in the treatment of idiopathic pes equinovarus. Int Orthop 37: 1821-1825, 2013.

OŠŤÁDAL M, ECKHARDT A, HERGET J, MIKŠÍK I, DUNGL P, CHOMIAK J, FRYDRYCHOVÁ M, BURIAN M: Proteomic analysis of the extracellular matrix in idiopathic pes equinarus. Mol Cell Biochem 401: 133-139, 2015.

PANDEY S, PANDEY AK: The classification of clubfoot a practical approach. Foot 13: 61-65, 2003.

PENG H, HORZOG EL: Fibrocytes: emerging effector cells in chronic inflammation. Curr Opin Pharmacol 12: 491-496, 2012.

PONSETI IV, SMOLEY EN: Congenital club foot: results of treatment. J Bone Joint Surg Am 45: 261-266, 1963.

PONSETI IV, ZHIVKOV M, DAVIS N, SINCLAIR M, DOBBS MB, MORCUENDE JA: Treatment of the complex idiopathic clubfoot. Clin Orthop Relat Res 451: 171-176, 2006.

POON R, LI C, ALMAN BA: Beta-catenin mediates soft tissue contracture in clubfoot. Clin Orthop Relat Res 467: 1180-1185, 2009.

SABATELLI P, GUALANDI F, GARA SK, GRUMATI P, ZAMPARELLI A, MARTONI E, PELLEGRINI C, MERLINI L, FERLINI A, BONALDO P, MARALDI NM, PAULSSON M, SQUARZONI S, WAGENER R: Expression of collagen VI $\alpha 5$ and $\alpha 6$ chains in human muscle and in Duchenne muscular dystrophy-related muscle fibrosis. Matrix Biol 31: 187-196, 2012.

SABATELli P, PALMA E, ANGELIN A, SQUARZONI S, URCIUOLO A, PELLEGRINI C, GUALANDI F, MERLINI L, BERNARDI P, MARALDI NM: Critical evaluation of the use of cell cultures for inclusion in clinical trials of patients affected by collagen VI myopathies. J Cell Physiol 227: 2927-2935, 2012.

SANO H, UHTHOFF HK, JARVIS JG, MANSINGH A, WENCKEBACH GFC: Pathogenesis of soft-tissue contracture in club foot. J Bone Joint Surg Br 80: 641-644, 1998.

SLUIJS JA, PRUYS JE: Normal collagen structure in the posterior ankle capsule in different types of clubfeet. J Pediatr Orthop B 8: 261-263, 1999.

VIJAYARAGAVAN E, KURIAN LM, SULAYMAN H, GOPAL TV: Application of rapid prototyping in the treatment of clubfoot in children. Procedia Engineering 97: 2298-2305, 2014.

WEYMOUTH KS, BLANTON SH, BAMSHAD MJ, BECK AE, ALVAREZ C, RICHARDS S, GURNETT CA, DOBBS MB, BARNES D, MITCHEL LE, HECHT JT: Variants in genes that encode muscle contractile proteins influence risk for isolated clubfoot. Am J Med Genet A 155A: 2170-2179, 2011.

WEYMOUTH KS, BLANTON SH, POWELL T, PATEL CV, SAVILL SA, HECHT JT: Functional assessment of clubfoot associated HOXA9, TPM1, and TPM2 variants suggests a potential gene regulation mechanism. Clin Orthop Relat Res 474: 1726-1735, 2016. 
WINDISCH G, SALABERGER D, ROSMARIN W, KASTNER J, EXNER GU, HALDI-BRÄNDLE V, ANDERHUBER F: A model for clubfoot based on micro-CT data. $J$ Anat 210: 761-766, 2007. 